\title{
Antioxidative Potential, Antibiofilm Activity and Partial Chemical Characterization of Cultured Broth after Pleurotus ferulae Mycelium Cultivation
}

\author{
EMANUEL VAMANU1*, OANA LIVADARIU ${ }^{1}$, IONELA SARBU ${ }^{2}$, MIHAELA ENE ${ }^{3}$, IOAN DOPCEA ${ }^{1,4}$ \\ ${ }^{1}$ University of Agronomic Sciences and Veterinary Medicine, Faculty of Biotechnology, 59 Marasti Blvd., 011464, Bucharest, \\ Romania \\ 2 ICUB-Research Institute of the University of Bucharest 36-46 M. Kogalniceanu Blvd., 050107, Bucharest,Romania \\ ${ }^{3}$ Horia Hulubei National Institut for Physics and Nuclear Engineering, 30 Reactorului, 077125 Magurele, Romania \\ ${ }^{4}$ Eurofins Evic Product Testing Romania SRL, 64-66 Marasesti Blvd., 040256, Bucharest, Romania
}

\begin{abstract}
The purpose of the present study was to assess the antioxidant effect, antibiofilm activity, and partial characterization of the main groups of bioactive compounds of mushrooms, under the influence of the composition of the relevant culture environment and differentfermentation parameters of the Pleurotus $(P$. ferulae mushroom mycelium. One used five carbon sources $(1.0 \mathrm{~g}, 2.5 \mathrm{~g}$, and $5.0 \mathrm{~g} / 100 \mathrm{~mL})$, which included glucose, sorbitol, starch, lactose, and sucrose, and of the fermentation parameters, the variation was characteristic for temperature $\left(21,23\right.$, and $\left.25^{\circ} \mathrm{C}\right)$, and the $\mathrm{pH}$ values varied between 5 and 8 . Following a review of the data and the statistical correlation of results, an optimum level of culture environment was found: $2.5 \mathrm{~g} / 100 \mathrm{~mL}$ of glucose, at a temperature of $21^{\circ} \mathrm{C}$, and a $\mathrm{pH}$ value of 5 . Under such circumstances, the antioxidant activity exhibited a certain correlation with the level of the primary bioactive compounds (phenolic acids, for instance), the antibiofilm effect against four bacterial strains, and the outcomes were confirmed by showing the essential statistical indices.
\end{abstract}

Keywords: mycelium, exopolysaccharides, radical scavenging activity, glucose

Pleurotus ferulae is a species that one does not normally find in the common Romanian flora, yet it flourish seasonally, particularly in the fall. It is specific to Asian cooking, where it is also highly appreciated due to its medicinal properties, which are less valued in European countries. In vivo studies have shown that the frequent use of such mushrooms leads to an increase in cholesterol removal, and it also has protective effects at the hepatic level [1]; yet, the ethanol extract from the fructification body has proven to have great potential therapeutic effects in terms of treating cancer [2]. From this perspective, the pharmaceutical value of the species is constantly increasing given the interest in developing some new biopharmaceutical products capable of acting against such a widely spread pathologies in the population.

The controlled growth of the mycelium of the duly concerned species can serve as an efficient alternative to getting bioactive compounds of pharmacological interest [3]. Some of the main bioactive compounds are the polysaccharides. Exopolysaccharides are easily obtained through submersed growth or batch growth, and their biological action depends on their molecular mass, the structure of the polymer, and other relevant compounds that may be withheld by the polymer during such growth (for instance, phenolic compounds) [4]. Exopolysaccharides are directly correlated with antioxidant activity, and with the phenolic component that can be easily recovered by growing them in a fluid environment. Such phenolic components have an impact on the antiradical in vitro action of polysaccharides that are obtained when growing the mycelium [5]. Thus, the purpose of the present study purpose is to evaluate the antioxidant effects, antibiofilm activity, and partial characterization of the main groups of bioactive compounds in response to the composition of the relevant growth environment and the variation of the fermentation parameters in terms of $P$. ferulae mushroom mycelium.

\section{Experimental part}

Materials and Methods

Chemicals

All chemicals and reagents were purchased from SigmaAldrich Co. (St. Louis, MO, USA). All other unlabeled chemicals and reagents were of analytical grade.

Mycelium cultivation and fermentation conditions

P. ferulae mycelium was obtained and was authenticated by Andrei Macoveiciuc, Dali, Cyprus. The corresponding number for specimen was specified in the 17031724CO. The mycelia were kept in Nalgene cryotubes grown on barley grains, in $20 \%$ glycerol, at $-80^{\circ} \mathrm{C}$ [5]. The mycelia were revitalized on the medium of malt extract agar (M6907; Sigma-Aldrich Co.). The inoculums were prepared by growing the mushrooms on a LabTech rotary shaker at $150 \mathrm{rpm}$ for 5 days, at $23^{\circ} \mathrm{C}$, in $250 \mathrm{~mL}$ Erlenmeyer flasks containing $100 \mathrm{~mL}$ of the culture medium with $5 \mathrm{~g}$ of starch, $1 \mathrm{~g}$ of peptone, $0.26 \mathrm{~g}$ of $\mathrm{KH}_{2} \mathrm{PO}_{4^{\prime}} 0.02 \mathrm{~g}$ of $\mathrm{MgSO}_{4^{\prime}}$ and 0.01 $\mathrm{g}$ of $\mathrm{CaCl}_{2}$ per liter. The tests were made with different carbon sources like glucose, lactose, sucrose, starch, and sorbitol, at $5.0 \mathrm{~g}(\mathrm{G} 5), 2.5 \mathrm{~g}(\mathrm{G} 2.5)$, and $1.0 \mathrm{~g}$ (G1) per liter. Also, the tests were performed at different $p H$ levels and in different temperatures [6].

Analysis of biomass and polysaccharide production

After 7 and 14 days of fermentation, the mycelium biomass was separated by centrifugation at $4.000 \mathrm{~g}$ for 20 min. The obtained supernatant was mixed with pure ethanol (1:1) and left for $24 \mathrm{~h}$ at $4^{\circ} \mathrm{C}$. The precipitate containing polysaccharides was separated by centrifugation at $12.000 \mathrm{~g}$ for $15 \mathrm{~min}$ [7].

Antioxidant activity of the fermented culture medium

The level of antioxidant activity of the supernatant following mycelium removal by centrifugation was

*email@emanuelvamanu.ro; Phone: 0040742218240 
determined by DPPH scavenging activity [8], metal chelating ability, and power reduction [9].

Quantification of major antioxidant compounds from the fermented culture medium

Total phenolic and flavonoid contents were estimated by a colorimetric assay, which was described in a previous study [10].

Antibiofilm activity of the fermented culture medium

To assess the antibiofilm activity, we selected two Grampositive stains ( $B$. cereus, American Type Culture Collection [ATCC] 11778; S. aureus, ATCC 6538), two Gram-negative stains (E. coli ACTCC 25922; P. aeruginosa ATCC 15442), and one yeast stain (C. albicans, ATCC 10231). The microbial stains were seeded on BHI (bacteria) and YPG (yeast) medium, and incubated for $24 \mathrm{~h}$ at $37^{\circ} \mathrm{C}$.

In the 96-well plates, $100 \mu \mathrm{L}$ of medium $\mathrm{MH}$ (bacteria) and Roswell Park Memorial Institute (RPMI) 1640 with 0.165 M MOPS, $0.03 \%$ L-glutamine, and free bicarbonate (yeast) were added. Over the broth media $100 \mu \mathrm{L}$ from each extracts was added, and serial binary dilutions were performed. Finally, $10 \mu \mathrm{L}$ of microbial culture with the density of 0.5 McFarland was added in to the wells. The plates were incubated for $20 \mathrm{~h}$ at a temperature of $37^{\circ} \mathrm{C}$. After incubation the 96 plates were wash two times with PBS and the biofilm was stained with crystal violet $1 \%$ in methanol for 15 minutes. The dye was remove by washing with water and then was discolored with 33\% acetic acid solution. The optical density at $490 \mathrm{~nm}$ was measured in order to establish the minimum concentration for biofilm inhibition [11,12].

\section{Statistical analysis}

All parameters for antioxidant activity were assessed in triplicate, and the results were expressed as the mean \pm standard deviation (SD) values of three observations. The mean and SD were calculated with Excel (Microsoft Office 2016; MicrosoftCorporation, Redmond, WA, USA). The level of significance was set at $P \leq 0.05$. The IBM SPSS Statistics software (IBM Corporation, Armonk, NY, USA) was used to analyze and correlate the experimental data.

\section{Results and discussions}

The compositions of cultured broth demonstrated high antioxidant activity (free radical scavenging activity) depending on the carbon sources and concentrations (table 1). The most productive carbon source was glucose, which was present at a concentration of $2.5 \%$. The antioxidant capacity was directly dependent on concentration, with a drop of over $60 \%$ upon doubling the quantity. The same trend was also determined in terms power reduction, which was construed as a type of degradation of various bioactive compounds that express this very property (for example, ascorbic acid).

These results were not correlated with other carbon sources, as duly used. For instance, sugar triggered a positive correlation between biomass quantity and the quantity of phenolic compounds (fig. 1). Conversely, even though the antioxidant potential had a positive value, it was not directly proportional to the accumulation of the overall quantity of bioactive compounds in the fermented medium.

The rest of tested sources showed differentiated values for each single quantity, as concerned. The exception was sorbitol, where a quantity of $5 \%$ triggered an inversely proportional relationship between the accumulation of the biomass and the overall accumulation of phenolic compounds. As in the case of sugar, the antioxidant potential was low $(15.61 \% \pm 0.10 \%$ for the antiradical capacity).

Upon increasing the temperature by $2^{\circ} \mathrm{C}$, the determined parameters registered some drops between 10 and $20 \%$. A decrease in the fermentative characteristics of mycelium growth in a fluid environment was also observed. Mycelium agglomerations are small in terms of diameter, and they tend to liquefy, so they should be grown in the presence of sorbitol (data not shown). The drop in the quantity of the biomass and the disaggregation of mycelium agglomeration have illustrated that there was a significant loss in the value of biological activities, which matched the lowering of the phenolic component level.

Instead, upon dropping the temperature by $2^{\circ} \mathrm{C}$, one may notice that there is a major variation in the accumulated biomass. The increase and drop in the $\mathrm{pH}$ value by approximately 1.5 units triggered the reduction of biomass
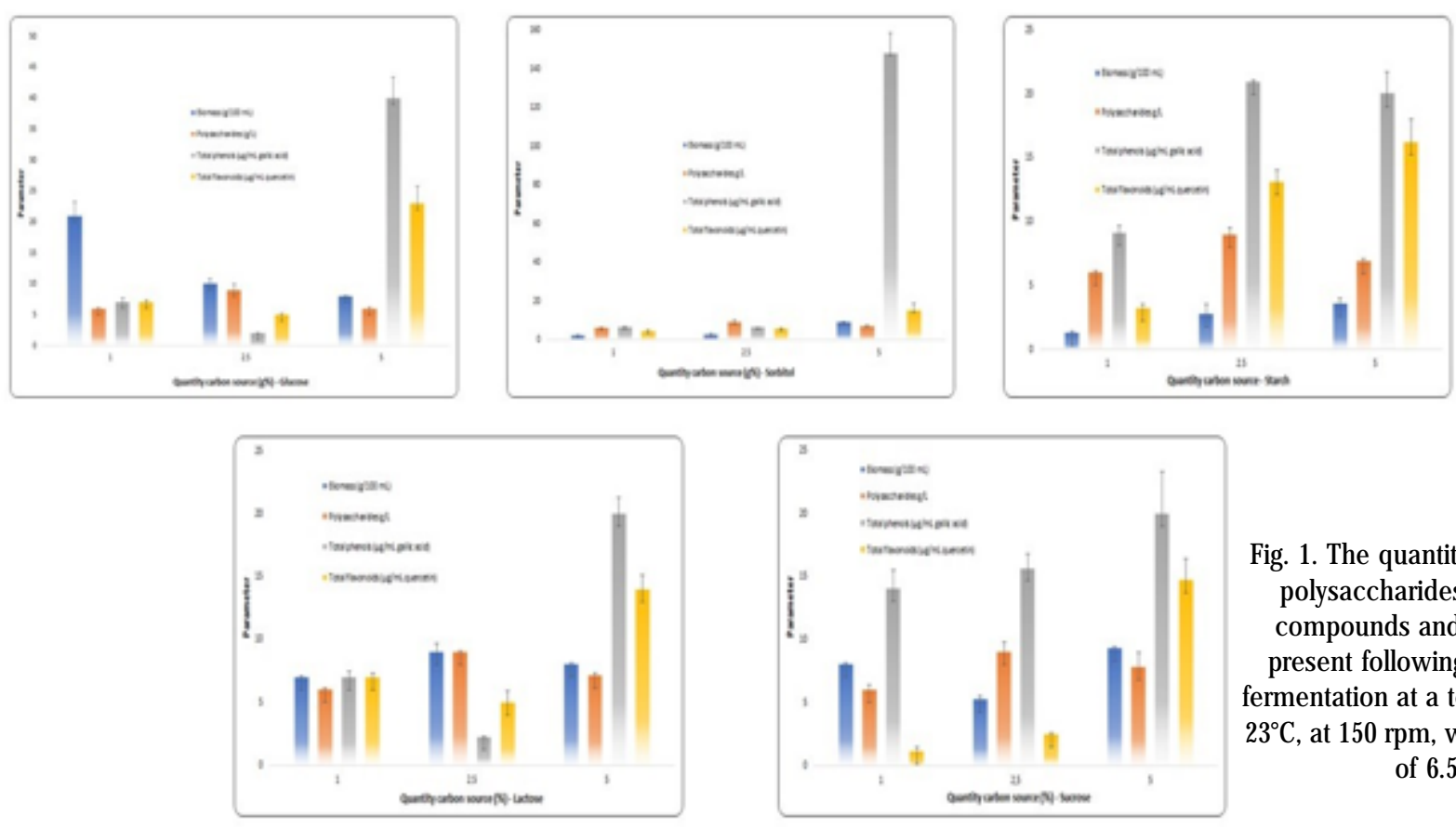

Fig. 1. The quantity of biomass, polysaccharides, phenolic compounds and flavonoids present following 14 days of fermentation at a temperature of $23^{\circ} \mathrm{C}$, at $150 \mathrm{rpm}$, with a $\mathrm{pH}$ level of 6.5 . 
accumulation. The analysis of bioactive compound accumulation (fig. 2) showed a positive evolution. The overall quantity of phenolic compounds increased by $64.70 \pm 0.05 \%$, at $p \mathrm{H}$ level of 8 . The sole difference was noticed upon the accumulation of polysaccharides in the fermented medium; how ever, this behavior was correlated with the increased presence of internal polysaccharides, representing stress-related outcomes under the conditions of the fermentation process. This triggered an upper biological value of the relevant biomass.

The biofilm mass was directly proportional to color intensity. The M1 and M2 extracts stimulate $E$. coli ATCC 25922 to form biofilm, but on the other bacterial strains these samples have no effect.

Concentration above $3.125 \%$ and respectively $1.562 \%$ from the extracts $\mathrm{Gl}$ ( $\mathrm{pH} 5$ and 8) and $\mathrm{G} 2.5$ ( $\mathrm{pH} 5$ and 8) reduces the formation of biofilm in the case of $E$. colistrain. Extract $\mathrm{G} 5$ exert the highest antibiofilm effect on $E$. coli strain, the concentration above $0.78 \%$ being able to reduce biofilm up to $50 \%$.

The extract $\mathrm{Gl}$ at $\mathrm{pH} 5$ and $\mathrm{pH} 8$ reduce the biofilm formatted by $S$. aureuSATCC 6538 while the concentration above $6.25 \%$ from the extracts $\mathrm{G} 2.5$ and $\mathrm{G} 5$ stimulate the bacterial strain to produce biofilm.

Concentration above $12.5 \%$ from the extracts $\mathrm{G} 1, \mathrm{G} 2,5$ and G5 seems to stimulate $P$. aeruginosa ATCC 15442 biofilm formation. The $B$. cereus ATCC 11778 and $C$. albicans ATCC 10231 strains did not show a high capacity to form biofilm.

Obtaining biomass by the submerged growth of $P$. ferulae mycelium and the accumulation of compounds that have antioxidant effects have been proven by their correlation with the expression of their antioxidant potential. Even if the maximum values for each single parameter were not registered for glucose, the latter triggered a concomitant linear expression in the accumulation of biomass with the presence of an antioxidantresponse in terms of the growth medium. These results were similar to those from previous studies, particularly those that grew $I$. obliquus in the presence of corn flour [6]. One negative finding was evident in the case of polysaccharide accumulation in the relevant medium, when the quantity failed to exceed $10 \mathrm{~g} /$ $L$ after 10 days of fermentation.

The influence of polysaccharide fraction has been directly dependent on the structure of the polymer, which may withhold even low quantities of phenolic compounds [3]. Although the purpose of the present study has notbeen represented by the analysis of the biological effect stated by these very compounds, one has noticed a certain direct relationship between the quantity being present in the relevant medium and one of the relevant phenolic compounds.

The interpretation is that the release of the two categories of bioactive compounds matches a common profile, as stimulated by the existence of a certain amount of stress during growth. In terms of the effect on biofilm formation, the relevant medium fermented by $P$. ferulae mycelium has had various effects. Samples with G2.5 and G5 have triggered the stimulation of $S$. aureus and $P$. aeruginosa strains to form such relevant biofilm, yet they lowered the capacity of such biofilm formation in terms of the E. coli strain (fig. 3). The results were interpreted as being representative of an effect resulting from the increase in polysaccharides and the selective reply triggered by the polyphenolic fraction. The Gl extract exert antibiofilm effect on $S$. aureus and $E$. colistrains especially at different $\mathrm{pH}$ values.

Thus, statistical analysis was performed, and regression coefficients were determined; the results are presented in table 2 . The $R^{2}$ coefficient was high for biomass (0.804) and polysaccharides (0.961). For bioactive compounds, flavonoids were highly correlated $(0.661)$ with the
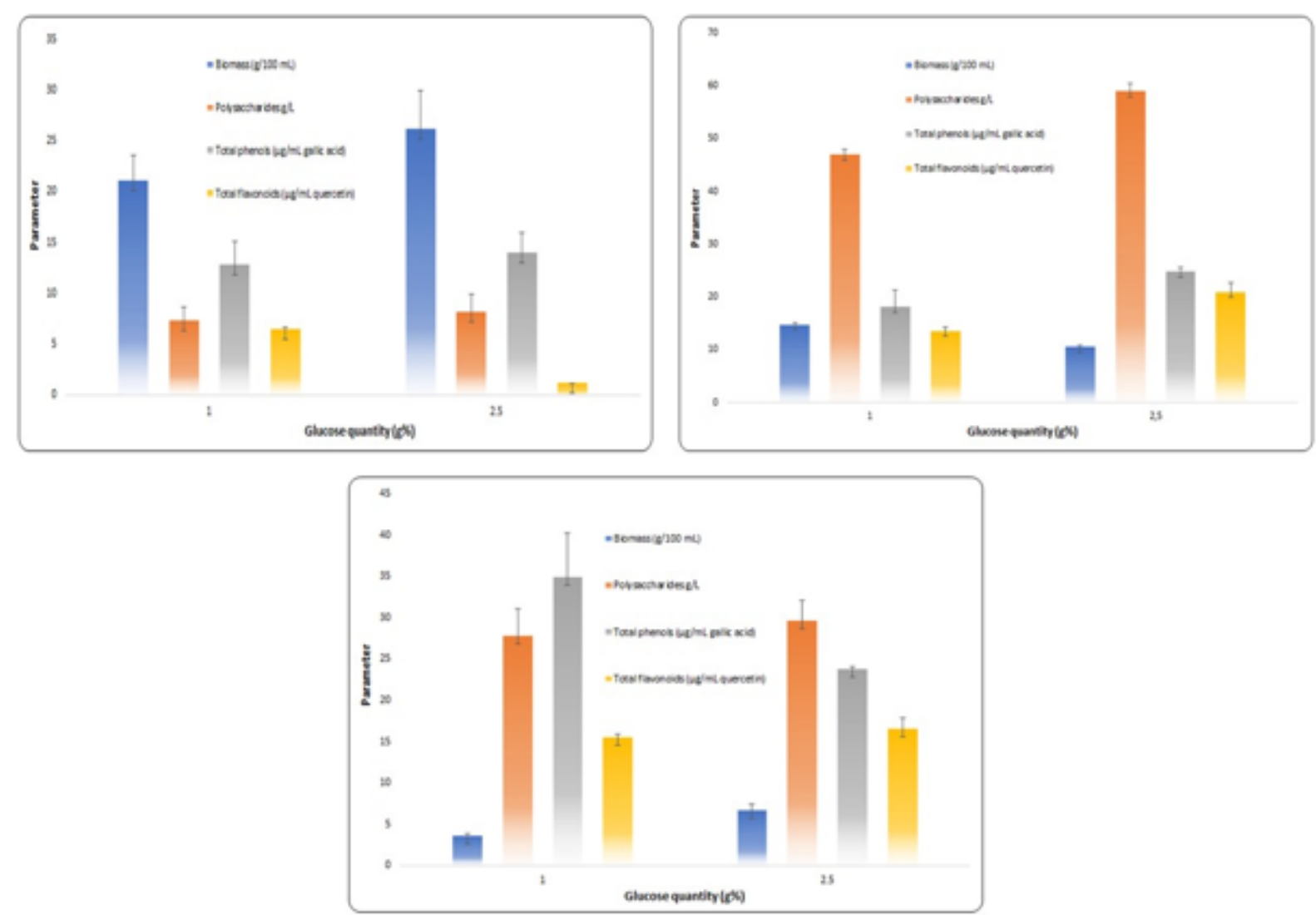

Fig. 2. The quantity of biomass, polysaccharides, phenolic compounds, and flavonoids present following 14 days of fermentation at a temperature of $21^{\circ} \mathrm{C}$, at $150 \mathrm{rpm}$, and at pH levels of 6.5-7.0 (top left), 5.0 (top right), and $8.0 \mathrm{pH}$ (middle, lower level) 


\begin{tabular}{|l|l|l|l|l|}
\hline $\begin{array}{c}\text { Parameter } \\
\text { (carbon source) }\end{array}$ & $\begin{array}{c}\text { Carbon source } \\
\text { concentration }\end{array}$ & $\begin{array}{c}\text { DPPH radical } \\
\text { inhibition }\end{array}$ & $\begin{array}{c}\text { Chelation } \\
\text { activity }\end{array}$ & $\begin{array}{c}\text { Reduction } \\
\text { power }\end{array}$ \\
\hline \multirow{4}{*}{ Glucose } & $\mathbf{1 . 0}$ & $09.03 \pm 0.09$ & $15.29 \pm 0.09$ & $0.51 \pm 0.03$ \\
\cline { 2 - 5 } & $\mathbf{2 . 5}$ & $44.18 \pm 0.01$ & $88.00 \pm 0.00$ & $0.66 \pm 0.02$ \\
\cline { 2 - 5 } & $\mathbf{5 . 0}$ & $16.57 \pm 0.08$ & $24.22 \pm 0.09$ & $0.55 \pm 0.00$ \\
\hline \multirow{4}{*}{ Lactose } & $\mathbf{1 . 0}$ & $11.78 \pm 0.06$ & $08.67 \pm 0.03$ & $0.35 \pm 0.01$ \\
\cline { 2 - 5 } & $\mathbf{2 . 5}$ & $19.83 \pm 0.13$ & $12.60 \pm 0.00$ & $0.38 \pm 0.10$ \\
\cline { 2 - 5 } & $\mathbf{5 . 0}$ & $10.98 \pm 0.15$ & $05.44 \pm 0.16$ & $0.49 \pm 0.06$ \\
\hline \multirow{3}{*}{ Sucrose } & $\mathbf{1 . 0}$ & $19.20 \pm 0.09$ & $11.67 \pm 0.07$ & $0.27 \pm 0.05$ \\
\cline { 2 - 5 } & $\mathbf{2 . 5}$ & $01.93 \pm 0.05$ & $21.01 \pm 0.05$ & $0.54 \pm 0.03$ \\
\cline { 2 - 5 } & $\mathbf{5 . 0}$ & $15.61 \pm 0.10$ & $18.00 \pm 0.03$ & $0.34 \pm 0.00$ \\
\hline \multirow{3}{*}{ Starch } & $\mathbf{1 . 0}$ & $15.25 \pm 0.04$ & $31.06 \pm 0.05$ & $0.50 \pm 0.08$ \\
\cline { 2 - 5 } & $\mathbf{2 . 5}$ & $16.53 \pm 0.06$ & $38.24 \pm 0.02$ & $0.59 \pm 0.05$ \\
\cline { 2 - 5 } & $\mathbf{5 . 0}$ & $17.72 \pm 0.02$ & $11.11 \pm 0.01$ & $0.46 \pm 0.05$ \\
\hline \multirow{3}{*}{ Sorbitol } & $\mathbf{1 . 0}$ & $10.73 \pm 0.04$ & $28.40 \pm 0.00$ & $0.43 \pm 0.07$ \\
\cline { 2 - 5 } & $\mathbf{2 . 5}$ & $36.70 \pm 0.03$ & $14.80 \pm 0.03$ & $0.58 \pm 0.08$ \\
\cline { 2 - 5 } & $\mathbf{5 . 0}$ & $19.86 \pm 0.08$ & $26.66 \pm 0.02$ & $0.53 \pm 0.08$ \\
\hline
\end{tabular}

Table 1

ANTIOXIDANT ACTIVITY OF THE FERMENTED ENVIRONMENT FOLLOWING THE GROWTH OF P. FERULAE MYCELIUM
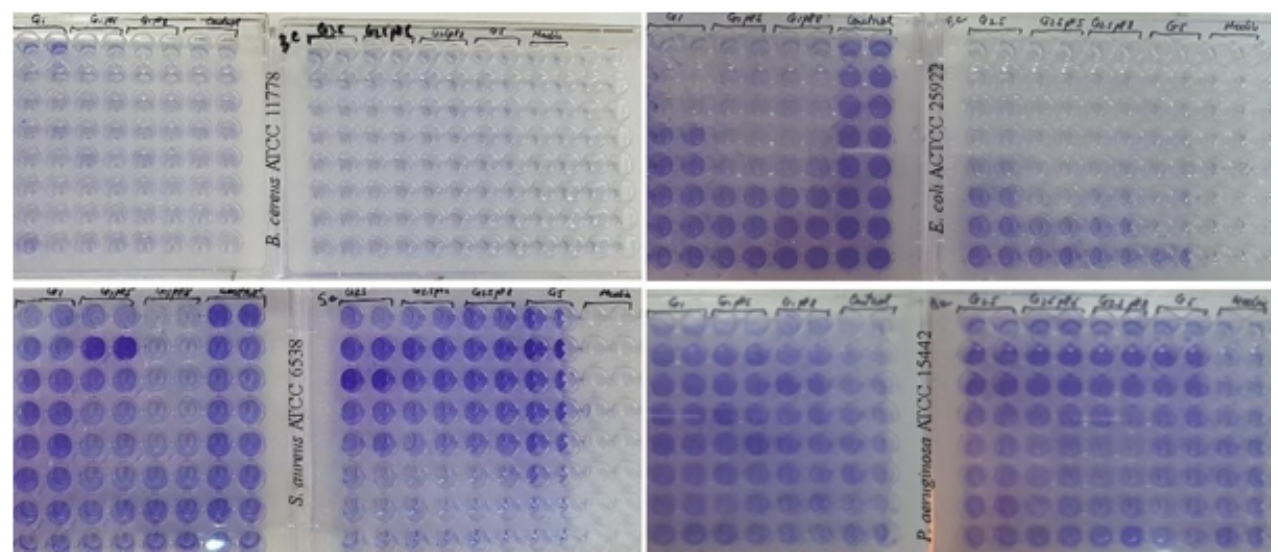

Fig. 3. Biofilm formed by bacterial strains in presence of mushroom extracts

Table 2

STATISTICAL ANALYSIS OF THE FERMENTATION PARAMETERS IN THE PRESENCE OF GLUCOSE

\begin{tabular}{|c|c|c|c|c|c|c|}
\hline \multirow[b]{3}{*}{ Variable } & & & & \multicolumn{3}{|c|}{ Biomass $(\mathrm{g} / 100 \mathrm{~mL})$} \\
\hline & \multicolumn{3}{|c|}{ Coefficients } & \multicolumn{2}{|c|}{ ANOVA } & \multirow[b]{2}{*}{$\mathrm{R}^{2}$} \\
\hline & $\begin{array}{l}\text { Regression } \\
\text { coefficient }\end{array}$ & $t$-value & Sig & $\mathrm{F}$ & Sig & \\
\hline Constant & 25.566 & 2.778 & 0220 & \multirow[b]{3}{*}{2.057} & \multirow[b]{3}{*}{0.442} & \multirow[b]{3}{*}{0.804} \\
\hline Glucose & -0.350 & -0.143 & 0909 & & & \\
\hline $\mathrm{pH}$ & 2.472 & 2.023 & 0.292 & & & \\
\hline \multicolumn{7}{|c|}{$\mathrm{Y}-25.566-0.350^{*} \mathrm{Glucoza}-2.472^{\star} \mathrm{pII}$} \\
\hline & & & & \multicolumn{3}{|c|}{ Polysaccharides $g / \mathrm{L}$} \\
\hline & \multicolumn{3}{|c|}{ Coefficients } & \multicolumn{2}{|c|}{ ANOVA } & \multirow[b]{2}{*}{$\mathrm{R}^{\mathrm{I}}$} \\
\hline Variable & $\begin{array}{l}\text { Reguessivn } \\
\text { coefficient }\end{array}$ & t-value & Sig & $\mathrm{F}$ & $\mathrm{S}_{1 \mathrm{~g}}$ & \\
\hline Constant & 35.072 & 6.656 & 0.095 & \multirow[b]{3}{*}{12.204} & \multirow[b]{3}{*}{0.193} & \multirow[b]{3}{*}{0.961} \\
\hline Glucose & 4.627 & 1.363 & 0.403 & & & \\
\hline $\mathrm{pH}$ & -8.057 & -4.749 & 0.132 & & & \\
\hline & & & & \multicolumn{3}{|c|}{$\mathrm{Y}=85.072+4.627^{*}$ Glucoza- $8.057^{*} \mathrm{pH}$} \\
\hline
\end{tabular}


Table 2

COTINUATED

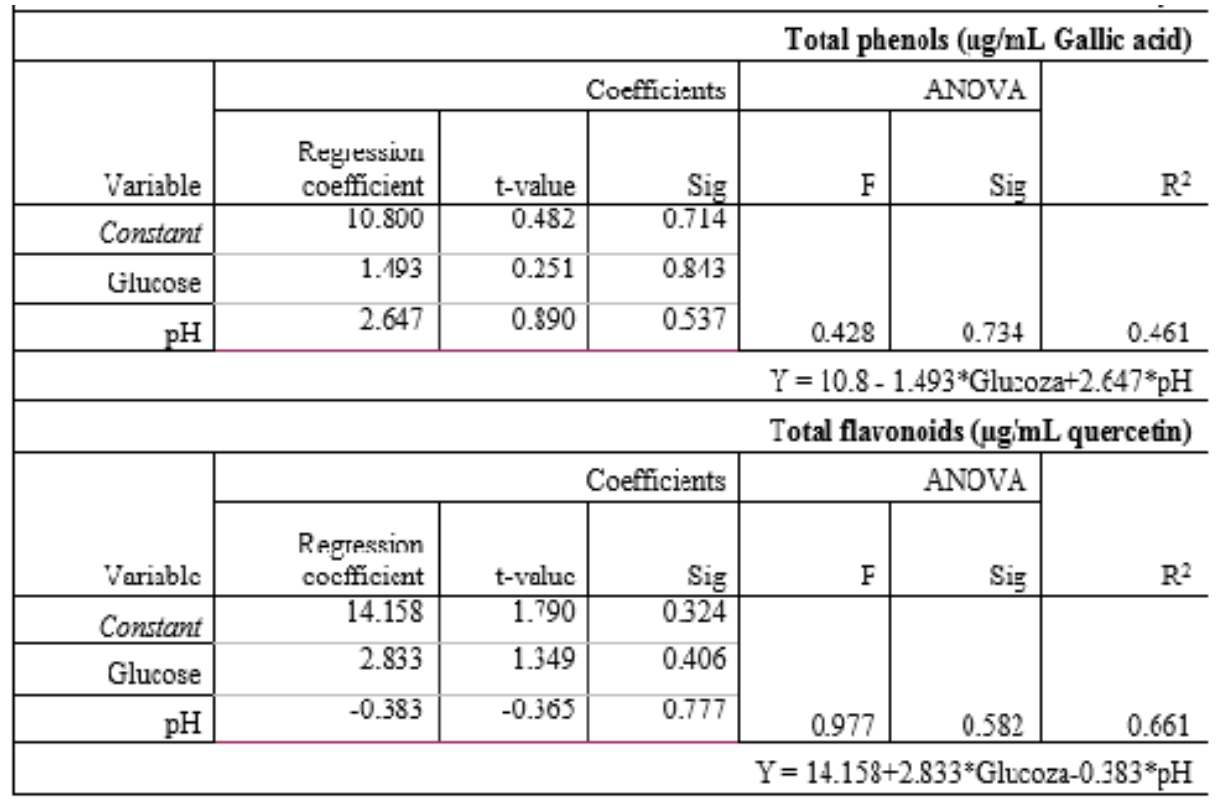

antioxidant potential of the fermentation broth. Significant data were determined from analysis of variance, and the $F$ value was high (12.204) in the case of polysaccharides. The $t$-value was expressed by the interaction between parameters ( $t=6.656$; $R=85.072$ ) for the same data (table 2) [6].

In the present study, a correlation between the experimental growth conditions and antioxidant potential was found, and it was associated with a high degree of accuracy in terms of the data duly described. The results highlighted the correlation between the composition of the fermentation medium, the level of bioactive compounds, and antioxidant potential. An average glucose level of $2.5 \%$ was determined to be optimal for the valorization of the polysaccharide fraction and the subsequent phenolic fraction, which were used to obtain functional products of high biological value.

Acknowledgments: English-language editing of this manuscript was provided by Journal Prep. This work was supported by the the Executive Agency for Higher Education, Research, Development, and Innovation Funding - Programme 1, Theme 171PED/2017. (http:// www.robiomush.ro/biochaga/)

\section{References}

1.ALAM, N., YOON, K.N., LEE, T.S., J. Res. Med. Sci., 16, 2011, p. 776.

2.WANG, W., CHEN, K., LIU, Q., JOHNSTON, N., MA, Z., ZHANG, F., ZHENG, X., Plos One, 9, 2014, e102673.

3.VAMANU, E., BioMed Res. Int., 2014, 2014, Article ID 974804.

4.LI., , YUAN,P,WANG, X.,AIPIRE, A., LI, M., YANG, J ., TAO, H., YING, T., FU, C., WEI, X., ZHANG, F., LI, J ., Food Funct., 24, 2017, p. 1905.

5.VAMANU, E., J. Biomed. Biotechnol., 2012, 2012, Article ID 565974. 6.HUI, C., XU, X., ZHU, Y., J. Microbiol. Biotechnol., 20, 2010, p. 835. 7.UMEO, S.H., SOUZA, G.P.N., RAPACHI, P.M., GARCIA, D.M., PACCOLAMEIRELLES, L.D., VALLE, J.S., COLAUTO N.B., LINDE, G.A., Gen. Mol. Res., 14, 2015, p. 9907.

8.KUO, C.F., WANG, T.S., YANG, P.L., JAO, Y.C., LIN, W.Y., J. Food Sci., 71, 2006, p. $\$ 456$.

9.VAMANU, E., NITA, S., Rev. Chim.(Bucharest), 65, 2014, p. 372. 10.VAMANU, E., ENE, M., PELINESCU, D., SARBU, I., VAMANU, A., NITA, S., Rev. Chim.(Bucharest), 62, 2011, p. 1189.

11.TURCU, I., ZARAFU, I., POPA, M., CHIFIRIUC, M. C., BLEOTU, C., CULITA, D., GHICA C.,IONITA, P., Nanomat., 7, 2017, p. 43.

12.SARBU, I., PELINESCU, D., STOICA, I., MARUTESCU, L., VASSU, T., Roum. Arch. Microbiol. Immunol., 72, 2013, p. 225.

Manuscript received: 12.03 .2018 